(c) American Dairy Science Association, 2006.

\title{
Productive Life Including All Lactations and Longer Lactations with Diminishing Credits
}

\author{
P. M. VanRaden, ${ }^{\star 1}$ C. M. B. Dematawewa, $\dagger$ R. E. Pearson, $\dagger$ and M. E. Tooker ${ }^{\star}$ \\ *Animal Improvement Programs Laboratory (AIPL), Agricultural Research Service, USDA, Beltsville, MD 20705-2350 \\ †Department of Dairy Science, Virginia Polytechnic Institute and State University, Blacksburg 24060
}

\begin{abstract}
Alternative measures of productive life (PL) were compared, and life expectancy factors were updated to replace estimates from 1993. Alternatives were proposed with extra credits for lactations longer than 10 mo and beyond $84 \mathrm{mo}$ of age and for each calving so that an extremely long lactation would not receive more credits than multiple shorter lactations with dry periods between. Maximum credits per lactation of 10 mo (original PL), $12 \mathrm{mo}$, and unlimited were compared. The unlimited credits option either included or excluded a calf value equal to 2 mo of production and had credits given for all days either uniformly or based on lactation curves (diminishing credits). Standard lactation curves (first, second, and greater lactations) were estimated based on the test-day yields of Holstein cows remaining in lactation from a set of 903,579 lactation records. For the diminishing credits alternative, credit for a given day of a parity was derived using the predicted yield of the day proportional to the average daily yield of the first $305 \mathrm{~d}$ of second parity. Daily yields were deviations from a baseline of $13.62 \mathrm{~kg}$. Heritabilities and genetic correlations were estimated by multitrait REML for alternative measures of PL, for longevity censored at various ages, and for yield traits and SCS in first parity. Data for REML analysis included records from 1,098,329 Holsteins born from 1994 through 1997 from 5,109 sires, and a relationship matrix among sires was included in the model. Lactations beyond 84 mo added little information. Heritability of PL was 0.073 with 10 mo, 0.069 with $12 \mathrm{mo}, 0.068$ and 0.067 with unlimited (uniform) lactation credits (with and without calf credits, respectively), and 0.070 with unlimited diminishing credits. Corresponding correlations among predicted transmitting abilities for PL and protein yield were $0.07,0.06,0.12,0.23$, and 0.09 , all much lower than the 0.46 estimated in 1993 . Heritability of PL with diminishing credits improved from 0.017 to 0.070 when cen-
\end{abstract}

Received December 21, 2005.

Accepted February 9, 2006.

${ }^{1}$ Corresponding author: paul@aipl.arsusda.gov soring age increased from 36 to 96 mo. There was no further increase in heritability beyond $96 \mathrm{mo}$. Genetic correlation with the final PL was 0.87 when PL was censored at $36 \mathrm{mo}$, but the estimate increased steadily with the censoring age. The PL with diminishing credits, which was favorable in both economic and genetic aspects, was desirable in crediting cows for complete lactations.

Key words: longevity, productive life, lactation length

\section{INTRODUCTION}

Longevity is now an important part of genetic selection in many countries. Dairy cattle breeders in the United States have used regional evaluations for 48mo stayability since 1984 (Everett, 1984) and national evaluations for productive life (PL) since 1994 (VanRaden and Wiggans, 1995) to select for longer-lasting cows. Approximate multitrait procedures were introduced (Weigel et al., 1998) and revised (VanRaden, 2001) to include correlated trait information in PTA for PL. The direct evaluation methods, projection factors, and definition of PL developed by VanRaden and Klaaskate (1993) continued in use as the first (singletrait) evaluation step, with new edits introduced in 2001 and 2002 to better account for herds that discontinued testing and for embryo donor dams, respectively.

Complete lactation records were not stored in the national database until 1997. The present definition of PL, originally introduced in 1994, has considered the total number of DIM up to 84 mo of age, with a limit of 305 DIM per lactation (VanRaden and Klaaskate, 1993). Most Holstein cows have lactations beyond 305 d (Tsuruta et al., 2005), but productive cows with extended lactations have been at a disadvantage under the present definition of PL because of their reduced opportunity to have more lactations. A new definition can now be used with credits for lactations beyond 305 d. The original definition of PL emphasized fertility because a separate US evaluation for female fertility prior to 2003 was lacking. With the availability of separate PTA for fertility since 2003 (VanRaden et al., 2004), the new definition of PL does not have to be a measure of fertility. 
Tsuruta et al. (2005) proposed several alternative definitions of PL, which included lactations of lengths up to 500 and $999 \mathrm{~d}$ ( $\mathrm{PL}_{500}$ and $\mathrm{PL}_{999}$, respectively) and herdlife (total days from first calving to culling). In those definitions and in the original definition, PL was a simple summation of all days accounted for by the respective definition, crediting for every day equally (uniform credit definitions). Alternatives such as $\mathrm{PL}_{500}$ and $\mathrm{PL}_{999}$ allowed cows to get credit for producing beyond $305 \mathrm{~d}$ but had undesirable genetic properties, such as reduced heritability $\left(0.08\right.$ for both $\mathrm{PL}_{500}$ and $\mathrm{PL}_{999}$ and 0.09 for herdlife compared with 0.10 under the original definition) and changes in genetic correlations with other economic traits used in predicting PL. Reductions of heritability in $\mathrm{PL}_{500}$ and $\mathrm{PL}_{999}$ are likely to be due to increased nongenetic influences on the trait with the inclusion of extended lactations. However, giving less credit to days late in lactation may reduce the loss in heritability when including days beyond 305 in PL.

A logical way to assign lesser credits to later stages of lactation is based on the diminishing economic impact associated with extended days of lactation. Lactation curves can provide diminishing credits for longevity based on economic value. Cows that begin a next lactation generally are more profitable than those that continue the previous lactation because a new peak yield is achieved. The credits of PL should account for the relative merit of new as well as extended lactations.

The goals of this research were to define PL by giving diminishing credits to DIM in lactations of unlimited length and to compare genetic properties of the new definition with those of the uniform credit definitions with a 10-mo limit (present definition), 12-mo limit, and unlimited credits (with or without calf credits equivalent to $2 \mathrm{mo}$ ). New factors were also obtained to predict final PL from variables available earlier in life. Methods were developed and tested using Holstein data, and final formulas were then applied to all breeds.

\section{MATERIALS AND METHODS}

\section{Development of Diminishing Credits for PL}

The diminishing credits approach to redefine PL imposed no restriction on age or lactation length of the cow. The credits were based on population lactation curves across $999 \mathrm{~d}$ of lactation. Test-day data, available at AIPL-USDA for Holstein cows that had calved from 1997 to 2003, were used to obtain the suitable prediction formulas for lactation curves for the population. After editing, there were 903,579 lactation records of 305,202 cows with lactation lengths varying from 5 to $999 \mathrm{~d}$. Initially, descriptive statistics such as means and frequency distributions of DIM were investigated for each parity to determine the variability in length of extended lactations of Holsteins. Three parity groups were defined as first, second, and third or greater (up to 9 lactations) based on the differences in shape of the lactation curves. Curves may differ for very old cows, but few records were available to estimate these shapes. Lactation curves for each parity group were fitted to the average daily yield of cows that remained in milk for each given day of lactation.

Lactation curves described in the literature (Wood, 1967; Rook et al., 1993; Dijkstra et al., 1997; Pollott, 2000) and the multiphasic curves of Grossman and Koops (1988) were tested using the PROC NLIN procedure in SAS (SAS Institute, 2000). However, the fit was poor for production beyond $305 \mathrm{~d}$, as seen earlier by Grossman and Koops (2003). During the later stages of extended lactations, the observed yields exceeded the predictions. This is in part due to the prediction curves in this study being based on only the cows still in milk at each day of lactation. Therefore, the following empirical model (a modification of the model of Dijkstra et al., 1997) was used to estimate the curves for each of the 3 parity groups:

$$
Y_{i, t}=\beta_{0, i}+\beta_{1, i} e^{\left[\beta_{2, i}\left(1-e^{-\beta_{3, i} t}\right) / \beta_{3, i}-\beta_{4, i} t\right]}
$$

where $Y_{i, t}$ is the average test-day yield on the $t$ th day in milk $(t=1,2, \ldots, 999)$ for the $i$ th parity group $(i=$ $1,2,3)$, and $\beta$ are curve parameters.

Cows must produce at a certain level to cover costs, and only when they exceed these costs can they produce a profit. Analogous to this concept, a baseline $\left(\beta_{5}\right)$ was imposed for all parities, and only the yield above the baseline $\left(Y_{i, t}-\beta_{5}\right)$ was credited in PL (Figure 1). Introduction of a baseline altered the credits assigned to each day of lactation and consequently improved the statistical properties of the PL derived. The baseline $\left(\beta_{5}\right)$ of $13.62 \mathrm{~kg}(=30 \mathrm{lb})$ was a compromise that slightly improved heritability of PL and was used for all parity groups.

The USDA recently changed from a mature equivalent basis to a 36-mo equivalent in adjusting for age. Thus, we chose the average daily yield during the first $305 \mathrm{~d}$ of the second parity $\left(\bar{Y}_{2,305}=35.09 \mathrm{~kg}\right)$ as the base milk yield for deriving credits. The credit for the $t$ th day in milk of the $i$ th parity group $\left(\omega_{i, t}\right)$ was equal to the yield deviation from the baseline on the $t$ th day in milk $\left(Y_{i, t}-\beta_{5}\right)$, proportional to $\bar{Y}_{2,305}-\beta$ :

$$
\begin{gathered}
\omega_{i, t}=\frac{Y_{i, t}-\beta_{5}}{\bar{Y}_{2,305}-\beta_{5}}= \\
\frac{\beta_{0, i}+\beta_{1, i} e^{\left[\beta _ { 2 , i } \left(1-e^{\left.\left.-\beta_{3, i} t\right) / \beta_{3, i}-\beta_{4, i} t\right]}-\beta_{5}\right.\right.}}{\left[\int_{1}^{305} \beta_{0,2}+\beta_{1,2} e^{\left[\beta_{2,2}\left(1-e^{\left.-\beta_{3,2} t\right) / \beta_{3,2}}-\beta_{4,2} t\right]\right.} d t\right] / 305-\beta_{5}} .
\end{gathered}
$$




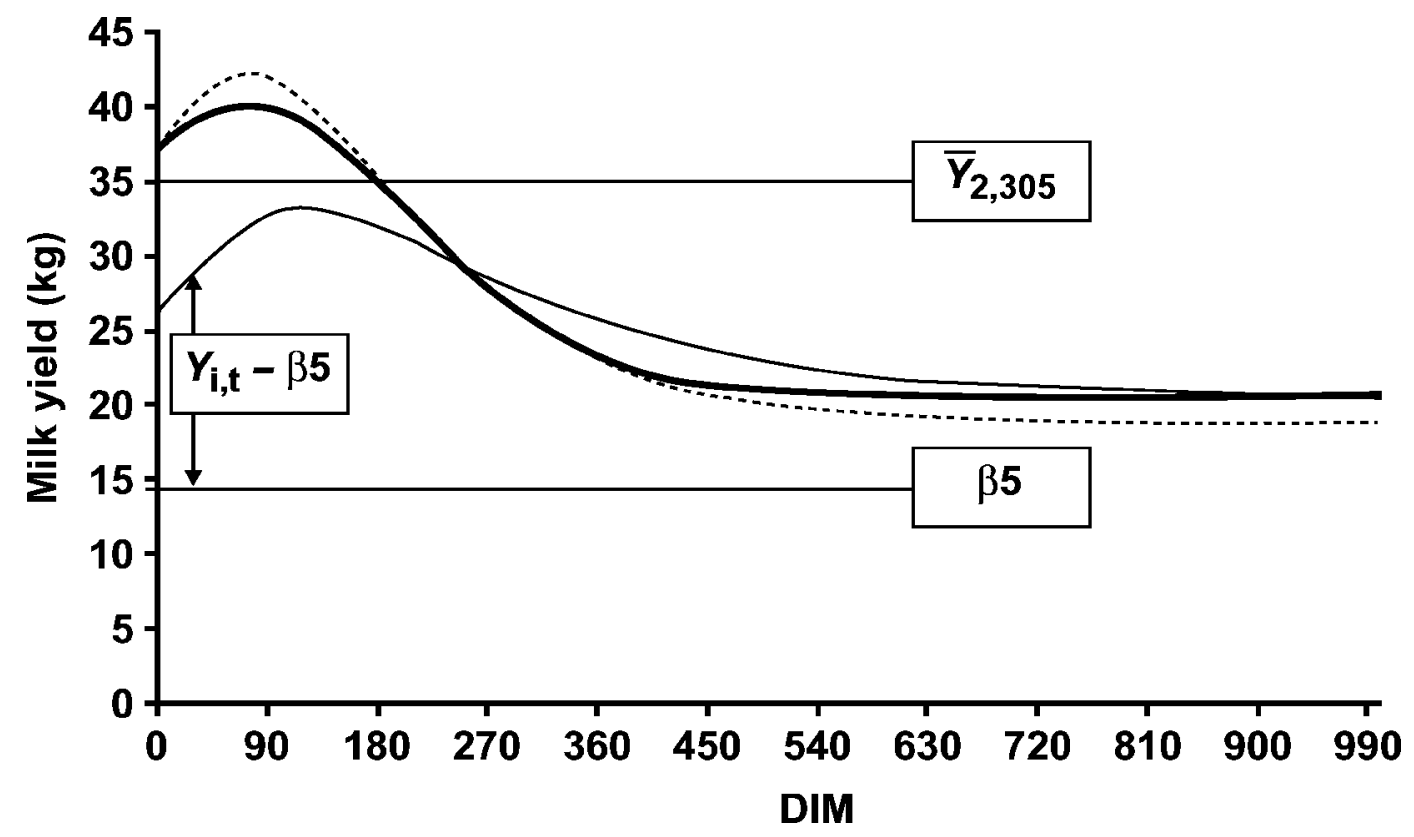

Figure 1. Lactation curves of cows remaining in lactation in the first parity (-), second parity (-), and third and other parities (- - -). The $Y_{i, t}, \bar{Y}_{2,305}$, and $\beta_{5}$ are the yield on the $t$ th day of milk in the first parity, average daily yield of the first $305 \mathrm{~d}$ of the second parity, and baseline $(13.62 \mathrm{~kg})$, respectively.

Note that

$$
\begin{aligned}
& \omega_{i, t}>1.0 \text { for } Y_{i, t}>\bar{Y}_{2,305} \\
& \omega_{i, t}=1.0 \text { for } Y_{i, t}=\bar{Y}_{2,305}
\end{aligned}
$$

and

$$
\omega_{i, t}<1.0 \text { for } Y_{i, t}<\bar{Y}_{2,305}
$$

Moreover, the credits given for each day a cow is in milk were always positive, because the baseline used was lower than the asymptotes of the 3 lactation curves (Figure 1). For the second lactation, a cow will earn a total of $305 \mathrm{~d}$ of PL credits if she has exactly 305 DIM. Finally, the PL with diminishing credits for a cow was defined as the summation of the credits earned for the DIM in all her lactations.

\section{Comparison of Alternative Definitions}

The new definition of PL with diminishing credits was compared with 4 alternative uniform credit definitions, with respect to their statistical and genetic properties. The first 3 uniform credit definitions were analogous to those studied by Tsuruta et al. (2005): Lactation credits were limited to 10 mo (the original trait defini- tion), to $12 \mathrm{mo}$, or were unlimited. Lactation credits in the fourth alternative definition were also unlimited, but a 2-mo credit was included for each calving to reward the beginning of a new lactation and to compensate for the standard 2-mo dry period. The calf credit was 2 mo even if the cow's dry period was shorter or longer than 2 mo. Heritability estimates of the 5 PL measures (main criterion) and their phenotypic and genetic correlations with other economic traits used in current PL evaluations were examined. In addition, correlations among the 5 definitions were also examined.

\section{Parameter Estimation and Genetic Evaluation}

Milk, fat, and protein yields; daughter pregnancy rate (DPR); SCS; service sire calving ease; and daughter calving ease (DCE) data were obtained from the November 2004 USDA-DHIA genetic evaluation system. Udder composite (UDC), feet and legs composite (FLC), and body size composite (BSC) data were obtained from the Holstein Association USA, Inc. (2004). For each of the 5 PL definitions, data from 1,098,329 cows born from 1994 through 1997 were used for a multitrait REML estimation of heritabilities and genetic correlations, including a relationship matrix among the 5,109 sires. Yield traits and SCS in first parity were included in the REML analysis, as well as longevity censored at ages 36, 42, 48, 54, 60, 72, 84, and 96 mo. Cows still 
Table 1. Cumulative frequency distribution of lactation length in different parities

\begin{tabular}{|c|c|c|c|}
\hline \multirow[b]{2}{*}{ DIM } & \multicolumn{3}{|c|}{ Parity group } \\
\hline & First & Second & $\begin{array}{l}\text { Third and } \\
\text { later }\end{array}$ \\
\hline$\leq 30$ & 1.45 & 1.32 & 2.14 \\
\hline$\leq 60$ & 4.13 & 3.84 & 6.09 \\
\hline$\leq 150$ & 9.62 & 10.37 & 15.43 \\
\hline$\leq 305$ & 38.42 & 41.47 & 46.26 \\
\hline$\leq 365$ & 65.73 & 68.88 & 70.90 \\
\hline$\leq 500$ & 90.61 & 93.48 & 93.71 \\
\hline$\leq 999$ & 100.00 & 100.00 & 100.00 \\
\hline Total no. of lactations & 305,202 & 238,472 & 359,905 \\
\hline
\end{tabular}

alive at each censoring age and those still alive in 2005 received credit for predicted remaining PL. Predictions were obtained using multiple linear regression on PL credits in the current lactation, on accumulated credits across lactations up to the censoring age, and on age at first calf, expressed in months as a deviation from 24 mo. Finally, longevity variables were constructed for 20.2 million Holstein cows born since 1960 and evaluated with the single-trait animal model used for routine evaluations (VanRaden and Wiggans, 1995). Correlations of the longevity variables with protein yield, DPR, SCS, UDC, FLC, BSC, and DCE were also estimated using PTA of sires with more than 1,000 daughters in the 1994 through 1997 subset.

\section{RESULTS AND DISCUSSION}

\section{Characteristics of Extended Lactations}

The importance of including DIM beyond 305 in PL evaluations is illustrated in Table 1. Average DIM of the first, second, and greater parities were 336,322 , and $306 \mathrm{~d}$, respectively, with an overall mean of $320 \mathrm{~d}$. More than $50 \%$ of the cows had lactations longer than 305 d (Table 1). Between 29 and $35 \%$ of the cows were still in milk beyond $365 \mathrm{~d}$. However, $90 \%$ of the lactations in the first, second, and greater parities were less than 494, 465, and $461 \mathrm{~d}$ in length, respectively. These results show that the majority of cows are affected when zero credits are given for producing beyond $305 \mathrm{~d}$ (the present definition of PL).

The cows in the 3 parity groups that milked beyond $500 \mathrm{~d}$ had, on average, 305-d mature-equivalent yields of $12,037,11,911$, and $11,484 \mathrm{~kg}$, respectively, whereas the rest of the cows in the respective groups recorded $11,365,11,131$, and $10,720 \mathrm{~kg}$. The cows with extended lactations showed no difference in peak yields compared with the rest of the cows. It is likely that many nongenetic reasons are behind the extremely long lactation records. Thus, a reduction of credits given to the period
Table 2. Parameter estimates of the empirical model for the 3 parity groups with baseline yield $\left(\beta_{5}\right)$ subtracted

\begin{tabular}{llcl}
\hline & \multicolumn{3}{c}{ Parity group } \\
\cline { 2 - 4 } Parameter & First & Second & $\begin{array}{l}\text { Third and } \\
\text { later }\end{array}$ \\
\hline$\beta_{0}$ & 20.5192 & 20.5576 & 18.8050 \\
$\beta_{1}$ & 5.7143 & 16.6899 & 17.6889 \\
$\beta_{2}$ & 0.0224 & 0.0385 & 0.018 \\
$\beta_{3}$ & 0.0108 & 0.00162 & 0.00826 \\
$\beta_{4}$ & 0.00597 & 0.0342 & 0.0098 \\
$\beta_{5}$ & 13.62 & 13.62 & 13.62 \\
\hline
\end{tabular}

beyond $305 \mathrm{~d}$ seems justifiable when extended lactations are included in PL evaluations.

\section{Development of a New Definition of PL}

The empirical model used to derive the lactation curves provided a highly significant fit $(P<0.0001)$ for all 3 parity groups with an $\mathrm{R}^{2}$ value of 0.999 . The parameter estimates defining the 3 curves are given in Table 2 . The estimates showed that the asymptotic yields $\left(\beta_{0}\right)$ were $>18 \mathrm{~kg}$ in all 3 groups. The average yield of the animals in production beyond $600 \mathrm{~d}$ was nearly constant for each lactation group (Figure 1). First-parity cows had higher yields during the latter stage of extended lactations, although their peak (33.11 $\mathrm{kg}$ ) was lower than those of the other 2 groups (40.03 and $42.01 \mathrm{~kg}$, respectively). The 305-d yields for the 3 parity groups were $9,364,10,701$, and $10,876 \mathrm{~kg}$, respectively, with heifers producing about $86 \%$ of their mature yield, as expected. The 3 parity groups were similar in their 999-d average yields $(24,781,25,365$, and 24,654 $\mathrm{kg}$, respectively), counterbalancing the differences in peak yields by the greater persistency in first lactation.

Figure 2 shows that the credits (for cows in milk at each DIM) of the second and third parity groups under the PL with diminishing credits were $>1.0$ up to $d 178$ and 180, respectively; during that time, the daily yields were greater than $\bar{Y}_{2,305}$ and then gradually decreased following their respective lactation curves. Average daily yields of first-parity cows did not reach $\bar{Y}_{2,305}$; hence, their credits were below 1.0 throughout the lactation but were higher than those of the other parities during the latter stages of lactation owing to the higher persistency of first-parity cows. The credits received for the 999th day in milk were $0.33,0.32$, and $0.24 \mathrm{~d}$, respectively, for the 3 parities. In fact, beyond 24 mo of milk, approximately 3 (for the first- and second-parity groups) or 4 (for the third-parity group) lactation days were equivalent to $1 \mathrm{~d}$ of PL.

For the second parity, the cumulative PL credits earned were greater than DIM prior to the 305th day, were exactly equal to DIM on the 305th day, and were 


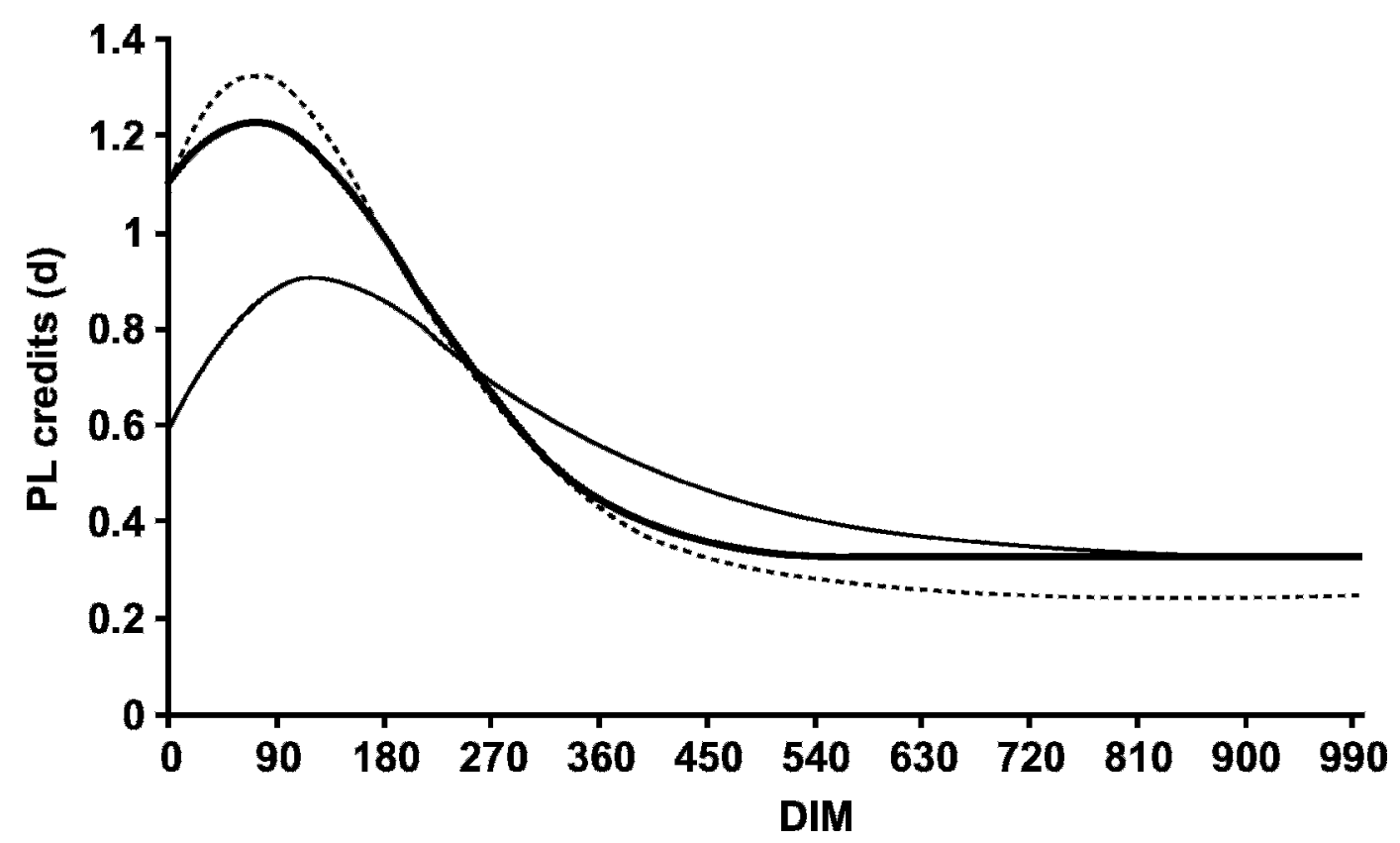

Figure 2. Credits (in days) given to each DIM during lactation in deriving productive life (PL) based on diminishing credits for the first parity (-), second parity (-), and third and other parities (- - -).

less than DIM thereafter (Table 3), because the 305-d yield of the second parity was the basis for the derivation of credits. Cumulative PL credits earned during the first parity were always lower than the respective DIM (Table 3), because daily credits were below 1.0 throughout the first lactation (Figure 2). However, for the third-parity group, cumulative PL credits were greater than the respective DIM up to the 322nd day of lactation. Because the 999-d total yields were approximately similar in all 3 groups, the respective PL credits earned for 999 DIM were also in close range (Table 3).

\section{Properties of Alternative Measures of PL}

Heritabilities for the 5 PL trait definitions are shown in Table 4 along with correlations of PTA for the 5,109 sires included in the REML analysis. Heritabilities were slightly lower than those reported by Tsuruta et al. (2005) but followed the same declining trend as the limit for lactation length increased. Heritability in- creased slightly when the calf value was included and also when diminishing credits replaced uniform credits. The correlation of 12 mo with unlimited credit was the lowest but was still greater than 0.95 . The lactation curve approach had a high correlation with the no-limit calf credit approach but had slightly higher heritability.

Correlation estimates of PL measures with protein yield, SCS, DPR, UDC, FLC, BSC, and DCE are shown in Table 5. Those estimates were based on PTA of the sires with more than 1,000 daughters $(n=195)$. The correlation estimates of the diminishing credits-based measure with protein yield, SCS, and DPR fell between the respective estimates of 10 -mo and unlimited uniform credits. However, the correlation estimates of diminishing credits-based PL with UDC, FLC, BSC, and DCE were essentially similar to those of the present definition of PL (10 mo). Using a multitrait sire model, Tsuruta et al. (2005) estimated the genetic correlations of the 10-mo and unlimited uniform credits to be -0.12 and 0.10 with protein yield and -0.32 and -0.27 with

Table 3. Cumulative productive life credits (in days) received by cows in the 3 parity groups with respect to DIM during lactation

\begin{tabular}{lllllll}
\hline & \multicolumn{7}{c}{ DIM } \\
\cline { 2 - 7 } Parity group & 60 & 150 & 305 & 365 & 500 & 999 \\
\hline First & 42.9 & 122.8 & 242.7 & 278.2 & 343.3 & 520.6 \\
Second & 70.7 & 177.8 & 305.0 & 334.9 & 385.6 & 547.7 \\
Third and later & 73.2 & 186.8 & 313.1 & 342.0 & 388.7 & 514.6 \\
\hline
\end{tabular}


Table 4. Heritabilities (on the diagonal) for 5 productive life (PL) measures and correlations of sire evaluations

\begin{tabular}{llllll}
\hline $\begin{array}{l}\text { PL credit limit } \\
\text { per lactation }\end{array}$ & $\begin{array}{l}\text { 10 mo } \\
\text { (uniform) }\end{array}$ & $\begin{array}{l}12 \text { mo } \\
\text { (uniform) }\end{array}$ & $\begin{array}{l}\text { No limit } \\
\text { (uniform) }\end{array}$ & $\begin{array}{l}\text { No limit }+ \\
\text { calf credit }\end{array}$ & $\begin{array}{l}\text { No limit } \\
\text { (diminishing) }\end{array}$ \\
\hline 10 mo (uniform) & 0.073 & 0.998 & 0.957 & 0.963 & 0.989 \\
12 mo (uniform) & & 0.069 & 0.956 & 0.961 & 0.989 \\
No limit (uniform) & & & 0.067 & 0.992 & 0.991 \\
No limit + calf credit & & & 0.068 & 0.995 \\
No limit (diminishing) & & & & & 0.070 \\
\hline
\end{tabular}

SCS, respectively. The corresponding estimates of the present study (for 10 mo and no limit in Table 5) were slightly more positive for protein yield. However, for SCS, our estimate was more negative under unlimited credits. Earlier, Tsuruta et al. (2004) had reported that the genetic correlation of the present PL varied between 0.00 and 0.22 with protein yield, -0.19 and 0.12 with BSC, and 0.29 and 0.44 with UDC during a period of $15 \mathrm{yr}$. The respective estimates in our study (10 mo in Table 5) were within the ranges reported by Tsuruta et al. (2004) for protein yield and BSC; however, the estimate for UDC was slightly below their range.

Differences in the estimates in the previous studies are most likely due to procedural differences in estimation as well as in sampling. The report of Tsuruta et al. (2004) was based on a set of Wisconsin Holstein cows born between 1979 and $1993(\mathrm{n}=25,280)$, whereas the values in Tsuruta et al. (2005) were from US Holsteins born from 1995 to 1997 ( $\mathrm{n}=392,800)$. In the present study, the intermediate correlation estimates received by the new definition of PL (values between those of 10-mo and unlimited uniform credits) are most likely due to the diminishing credits given to lactations beyond $305 \mathrm{~d}$.

\section{Early Measures of PL}

Properties of early measures of PL under the diminishing credits definition are compared in Table 6. The other definitions gave very similar patterns of correlation and heritability across censoring ages. Heritability of PL censored at 36 mo was only 0.017 , and the lower heritability at early censoring ages was accounted for in the linear model by using expansion factors and reduced weights, which were obtained from the phenotypic correlations of early with final PL (VanRaden and Klaaskate, 1993). As compared with estimates from 1993 (VanRaden and Klaaskate, 1993), early measures of PL were less heritable and less correlated with the final PL, perhaps because first-lactation cows are now kept longer before being culled. A delay in using PL records until 40 mo of age could prevent instability in early PTA, as indicated by the phenotypic and genetic correlations with final PL in Table 6.

Settar and Weller (1999) obtained higher correlations of censored PL with the final PL by including pregnancy diagnoses in early predictions. In US evaluations since 2003 , fertility information is included in the multitrait postprocessing step. Regression coefficients used to predict PL for cows still living are given in Table 7. The regressions shown are from the lactation curve definition; regressions for the other definitions followed a similar pattern and are not shown.

\section{Suitability of Alternative Measures}

Several longevity traits, such as number of lactations, the total length of life after first calving, length of life excluding dry periods, survival to a certain age, or multitrait analyses including other traits or treating survival in different lactations as different traits, can be evaluated using standard linear models. Alternatively, survival analysis can be used to account for changes in the probability of culling across time and may produce

Table 5. Correlations of PTA for 5 measures of productive life (PL) with protein yield, SCS, daughter pregnancy rate (DPR), udder composite (UDC), feet and legs composite (FLC), body size composite (BSC), and daughter calving ease (DCE)

\begin{tabular}{lllllrrr}
\hline $\begin{array}{l}\text { PL credit limit } \\
\text { per lactation }\end{array}$ & $\begin{array}{l}\text { Protein } \\
\text { yield }\end{array}$ & SCS & DPR & UDC & FLC & BSC & DCE \\
\hline 10 mo (uniform) & 0.07 & -0.34 & 0.72 & 0.20 & 0.06 & -0.17 & -0.33 \\
12 mo (uniform) & 0.06 & -0.35 & 0.72 & 0.19 & 0.04 & -0.17 & -0.32 \\
No limit (uniform) & 0.23 & -0.44 & 0.54 & 0.17 & -0.10 & -0.15 & -0.45 \\
No limit + calf credit & 0.12 & -0.36 & 0.59 & 0.19 & 0.05 & -0.18 & -0.34 \\
No limit (diminishing) & 0.09 & -0.36 & 0.64 & 0.20 & 0.05 & -0.17 & -0.33 \\
\hline
\end{tabular}


Table 6. Properties of productive life (PL) calculated with diminishing credits and censored at various ages or uncensored (final)

\begin{tabular}{lccccccccc}
\hline & \multicolumn{1}{c}{ Censoring age, mo } \\
\cline { 2 - 8 } PL statistic & \multicolumn{1}{c}{36} & \multicolumn{1}{c}{42} & 48 & 54 & 60 & 72 & 84 & 96 & Final \\
\hline Heritability & 0.017 & 0.029 & 0.037 & 0.045 & 0.052 & 0.062 & 0.067 & 0.070 & 0.070 \\
Phenotypic correlation with final PL & 0.47 & 0.62 & 0.72 & 0.80 & 0.86 & 0.93 & 0.97 & 0.99 & 1.00 \\
Genetic correlation with final PL & 0.87 & 0.93 & 0.96 & 0.98 & 0.99 & 1.00 & 1.00 & 1.00 & 1.00 \\
Phenotypic correlation with first-parity protein & 0.26 & 0.24 & 0.24 & 0.22 & 0.21 & 0.19 & 0.18 & 0.17 & 0.17 \\
Genetic correlation with first-parity protein & 0.24 & 0.18 & 0.17 & 0.13 & 0.11 & 0.08 & 0.06 & 0.06 & 0.05 \\
Phenotypic correlation with first-parity SCS & -0.13 & -0.14 & -0.14 & -0.14 & -0.14 & -0.14 & -0.14 & -0.14 & -0.14 \\
Genetic correlation with first-parity SCS & -0.33 & -0.34 & -0.35 & -0.35 & -0.36 & -0.36 & -0.38 & -0.38 & -0.38 \\
\hline
\end{tabular}

more accurate evaluations (Caraviello et al., 2004). The equations for survival analysis assign weights to daughter culling records that depend on changing culling rates that occur across time and across herds. These daughter weights may be optimal in a statistical sense, but can be difficult to interpret and might not be optimal in an economic sense.

The measures of PL compared in this study are simpler to interpret and can readily be incorporated as alternatives to the original definition of PL in the USDA-DHIA genetic evaluations. Of the alternative measures that considered extended lactations, the PL with diminishing credits was shown to have more desirable genetic properties while being able to account for the relative economic merit of DIM within and among lactations. Similar to the periodic base changes in yield traits, new credits can easily be derived periodically if lactation curves are found to be substantially different from those used earlier. Also, it may be appropriate to maintain breed-specific credits if lactation curves are substantially different in other breeds. Table $8 \mathrm{com}$ pares breed means and standard deviations of the new PL with diminishing credits and no limits to official PL with a 10-mo lactation limit and an 84-mo age limit. Cows born in 1997 were chosen to allow for complete PL records. Cows representing pure breeds were limited to those with $<25 \%$ heterosis, whereas crossbred cows had heterosis coefficients $\geq 25 \%$. Means increased by about $10 \%$ and standard deviations increased by about $40 \%$ because of the added credits for long lactations and for very old cows.

\section{CONCLUSIONS}

We proposed a revised economic definition of PL that gives credit for length of production using standard lactation curves. The previous definition focused on fertility by giving credit only to the first 10 mo of lactation. The revised PL had slightly higher correlations with other traits that influence culling, such as SCS and protein yield. The use of diminishing credits based on lactation curves of unlimited length was economically more sensible and had a slightly higher heritability of PL than simple extension of the 305-d limit per lactation or addition of credits for number of calvings but a slightly lower heritability than the original definition.

Genetic correlations of longevity and yield have declined across time, making simultaneous improvement of these 2 traits more difficult than in the past. Phenotypic correlations of PL with yield traits have not declined as much, indicating that the cause may be changes in cow physiology rather than culling practices. The revised prediction factors and parameter estimates should result in more stable and accurate PL evaluations. August 2006 implementation is expected.

\section{ACKNOWLEDGMENTS}

Helpful comments from Melvin Kuhn (AIPL), and cooperation from the dairy records processing centers in supplying DHIA data are greatly appreciated.

Table 7. Regressions of final productive life on variables for live cows at different ages of censoring

\begin{tabular}{lllllllll}
\hline & \multicolumn{7}{c}{ Censoring age, mo } \\
\cline { 2 - 9 } Regression variable & 36 & 42 & 48 & 60 & 72 & 84 & 96 & Dead $^{1}$ \\
\hline Intercept & 26.0 & 17.2 & 10.5 & 8.3 & 7.0 & 5.5 & 3.4 & 0.0 \\
Credit in current lactation & -0.015 & -0.020 & -0.015 & -0.013 & -0.013 & -0.013 & -0.013 & 0.0 \\
Accumulated credits & 0.82 & 1.44 & 1.59 & 1.36 & 1.25 & 1.20 & 1.17 & 1.0 \\
Age at first calf (mo) - 24 mo & -0.14 & 0.51 & 0.59 & 0.50 & 0.42 & 0.36 & 0.36 & 0.0 \\
\hline
\end{tabular}

${ }^{1}$ Any cow that is dead gets credit for her accumulated credits, and her other variables are then ignored. 
Table 8. Means and standard deviations (in months) of productive life (PL) by breed for cows born in 1997

\begin{tabular}{lll}
\hline & & $\begin{array}{l}\text { PL with no } \\
\text { limit and } \\
\text { diminishing } \\
\text { credits }\end{array}$ \\
\hline Breed & Official PL & $29.0 \pm 18.8$ \\
\hline Ayrshire & $25.9 \pm 12.5$ & $29.0 \pm 19.2$ \\
Brown Swiss & $25.3 \pm 12.7$ & $25.7 \pm 18.1$ \\
Guernsey & $23.0 \pm 12.9$ & $26.6 \pm 17.3$ \\
Holstein & $24.6 \pm 12.7$ & $32.6 \pm 19.6$ \\
Jersey & $29.3 \pm 13.3$ & $26.4 \pm 18.5$ \\
Milking Shorthorn & $25.5 \pm 13.0$ & $25.4 \pm 18.9$ \\
Crossbreeds $^{1}$ & - &
\end{tabular}

${ }^{1}$ Cows with heterosis $\geq 25 \%$ born in 1997 .

\section{REFERENCES}

Caraviello, D. Z., K. A. Weigel, and D. Gianola. 2004. Prediction of longevity breeding values for US Holstein sires using survival analysis methodology. J. Dairy Sci. 87:3518-3525.

Dijkstra, J., J. France, M. S. Dhanoa, J. A. Maas, M. D. Hanigan, A. S. Rook, and D. E. Beever. 1997. A model to describe growth patterns of the mammary gland during pregnancy and lactation. J. Dairy Sci. 80:2340-2354.

Everett, R. W. 1984. Northeast AI Multiple Trait Sire Comparisons. Cornell University, Ithaca, NY.

Grossman, M., and W. J. Koops. 1988. Multiphasic analysis of lactation curves in dairy cattle. J. Dairy Sci. 71:1598-1608.

Grossman, M., and W. J. Koops. 2003. Modeling extended lactation curves of dairy cattle: A biological basis for the multiphasic approach. J. Dairy Sci. 86:988-998.
Holstein Association USA, Inc. 2004. Linear Type Evaluations. Holstein Type-Production Sire Summaries. Holstein Association USA, Inc., Brattleboro, VT.

Pollott, G. E. 2000. A biological approach to lactation curve analysis for milk yield. J. Dairy Sci. 83:2448-2458.

Rook, A. J., J. France, and M. S. Dhanoa. 1993. On the mathematical description of lactation curves. J. Agric. Sci. 121:97-102.

SAS Institute. 2000. SAS User's Guide: Statistics. Version 8 ed. SAS Institute, Cary, NC.

Settar, P., and J. I. Weller. 1999. Genetic analysis of cow survival in the Israeli dairy cattle population. J. Dairy Sci. 82:2170-2177.

Tsuruta, S., I. Misztal, and T. J. Lawlor. 2004. Genetic correlations among production, body size, udder, and productive life traits over time in Holsteins. J. Dairy Sci. 87:1457-1468.

Tsuruta, S., I. Misztal, and T. J. Lawlor. 2005. Changing definition of productive life in US Holsteins: Effect on genetic correlations. J. Dairy Sci. 88:1156-1165.

VanRaden, P. M. 2001. Methods to combine estimated breeding values obtained from separate sources. J. Dairy Sci. 84(Suppl. E):E47-E55.

VanRaden, P. M., and E. J. H. Klaaskate. 1993. Genetic evaluation of length of productive life including predicted longevity of live cows. J. Dairy Sci. 76:2758-2764.

VanRaden, P. M., A. H. Sanders, M. E. Tooker, R. H. Miller, H. D. Norman, M. T. Kuhn, and G. R. Wiggans. 2004. Development of a national genetic evaluation for cow fertility. J. Dairy Sci. 87:2285-2292.

VanRaden, P. M., and G. R. Wiggans. 1995. Productive life evaluations: Calculation, accuracy, and economic value. J. Dairy Sci. 78:631-638.

Weigel, K. A., T. J. Lawlor, Jr., P. M. VanRaden, and G. R. Wiggans. 1998. Use of linear type and production data to supplement early predicted transmitting abilities for productive life. J. Dairy Sci. 81:2040-2044.

Wood, P. D. P. 1967. Algebraic model of the lactation curve in the cattle. Nature 216:164-165. 